\title{
Study on the Stochastic Model for Excessive Air Conditioning Use in Japanese Dwellings
}

\author{
Hikaru Imagawa ${ }^{1, *}$, Hom B. Rijal ${ }^{1}$, Masanori Shukuya ${ }^{1}$ \\ ${ }^{1}$ Graduate School of Environmental and Information Studies, Tokyo City University, Japan \\ Corresponding Email: h.imagawamh@gmail.com
}

\begin{abstract}
:
Thermal adjustment is one of the most important behaviours. In daily life, we use some behavioural adjustments. It is not always obtained the optimal condition by the thermal adjustments. For example, it happens to use excessive air conditioning for thermal adjustments. Especially, the excessive air conditioning use is important issue not only for the human comfort but also for the energy use. The occupant behaviour stochastic model was proposed by some previous researches around the world. However, these models show only the state of the occupant behaviour, and thus the excessive adjustments are not known. The objective of this research is to clarify quantitatively the excessive thermal adjustments which are happened to be in the stochastic model. The thermal measurement and occupant behaviour survey was conducted in 120 dwellings during 4 years period in Kanto region of Japan. The number of samples collected was 36,114 . We analysed the occupant behaviour stochastic model of the excessive cooling and heating use. The thermal sensation vote (TSV) and the thermal preference vote (TP) were used to classify the excessive air conditioning use. The proportion of excessive cooling use were increased when outdoor air temperature was increased. In addition, there were no significant difference between TSV and TP for calculating the proportion of the excessive air conditioning use in Japanese dwellings. These models are useful to understand the possibility of the energy saving. In the future, the model will be implemented in the building thermal simulation to predict the energy use in building.
\end{abstract}

Keywords: Occupant Behaviour, Excessive Air Conditioning Use, Stochastic Model, Thermal Sensation Vote, Outdoor Air Temperature, Japanese Dwellings

\section{Introduction}

Thermal adjustment is one of the most important behaviours. In daily life, we use some behavioural adjustments for thermal comfort and health. The occupant behaviours can be classified by "not using or using energy". The type of "not using energy" is called "passive control" such as clothing adjustment, window opening/closed. And the other is called "active control" such as fan, air conditioning and heater.

The stochastic model of occupant behaviours is one of the major parts of research. The stochastic models of occupant behaviours were analysed by many previous researches around the world [1-9]. Habara et al. [2,4] studied air conditioning use in Japanese dwellings. Takasu et al. [5] studied some major behaviours: window opening, air conditioning, and clothing adjustment in Japanese offices. Kim et al. [6] studied the air conditioning, fan, window and door in Australian dwellings.

In previous researches, the models of occupant behaviours were shown only the quantity of occupant behavioural opportunity. However, the previous model didn't show in detail that how many times the residents conducted these behaviours. Sometime we are unable to adjust the thermal adjustment properly from the view point of thermal comfort. If the opportunities of occupant behaviours are classified by residents' thermal sensation vote (TSV), we can establish the model of occupant behaviours based on resident's thermal comfort.

Thus, we proposed the models of excessive air conditioning use in previous studies $[7,8]$. These models were classified based on TSV 7 point scale: "when the resident voted in cold side ( $\mathrm{TSV} \leq 3)$ during the cooling use", it is defined as "excessive cooling use" and "when the residents voted in hot side $(5 \leq \mathrm{TSV})$ during the heating use", it is defined as "excessive heating use". In Japanese dwellings, we found that the proportion of the excessive cooling use is about $2-4 \%$ for the summer outdoor air temperature range, and the proportion of excessive cooling use was increased when the outdoor air temperature was decreased. The excessive heating use was less than $1 \%$ which is lower than the excessive cooling use. According to these comparisons, the possibility of comfort improvement and energy saving of the cooling use was bigger than heating use from the perspective of opportunity of AC use in Japanese dwellings. 
The spread of air conditioner in the Japanese dwellings is 90.5\% in 2013 (Figure 1) [10]. So, the air conditioning use is one of the most familiar thermal adjustment as active control in Japan. It is important to clarify the excessive air conditioning use for resident's health, comfort and energy saving. It is useful for better control of thermal adjustment behaviour.

In our previous studies, we used only TSV 7-point scale to classify the excessive air conditioning use. The TSV evaluated thermal comfort of residents which includes "hot" or "cold". However, we can also use other scales included the "human's desire" such as: would you like to adjust warmer or cooler? Thus, we also use the thermal preference (TP) 5-point scale to classify the excessive air conditioning use in this research.

The objectives of this study are to clarify quantitatively the excessive air conditioning use which are happened to be in the stochastic model based on the classification of the thermal sensation and thermal preference.

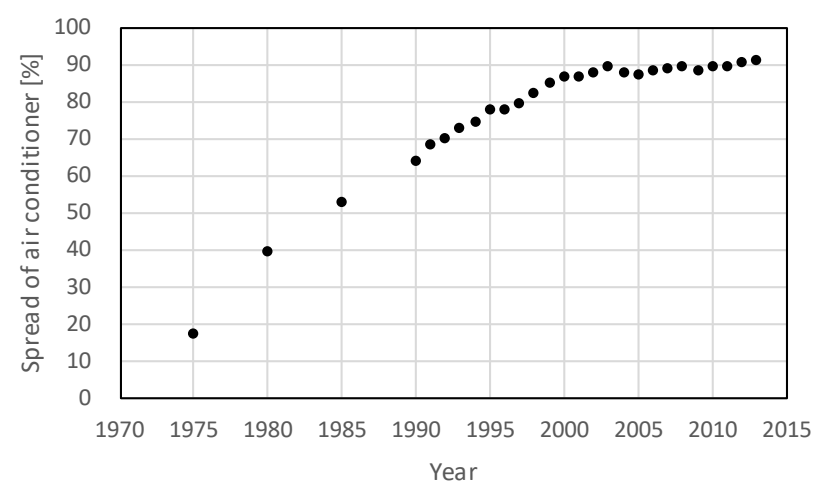

Figure 1: The spread of air conditioner in Japanese dwellings [10]

\section{Methodology}

\subsection{Field study}

The thermal measurement, thermal comfort survey and occupant behaviour survey was conducted in 120 dwellings during 4 years period in Kanto region of Japan (Tokyo, Kanagawa, Saitama and Chiba) [9]. The residents voted in living room and bedroom.

We measured the indoor air temperature in 10-minute interval. The height of the sensors is about $100 \mathrm{~cm}$ from the floor (Figure 2 and Table 1). The outdoor air temperature was obtained from the nearest meteorological station [11].

The residents voted thermal comfort and state of occupant behaviours in same time. The thermal comfort survey was conducted with 7-point thermal sensation and 5-point thermal preference (Table 2). The state of air conditioning use was recorded in binary form during the voting $(0=$ off, $1=$ on). The number of samples collected was 36,114 cases (living room: 22,386, bedroom: 13,728).

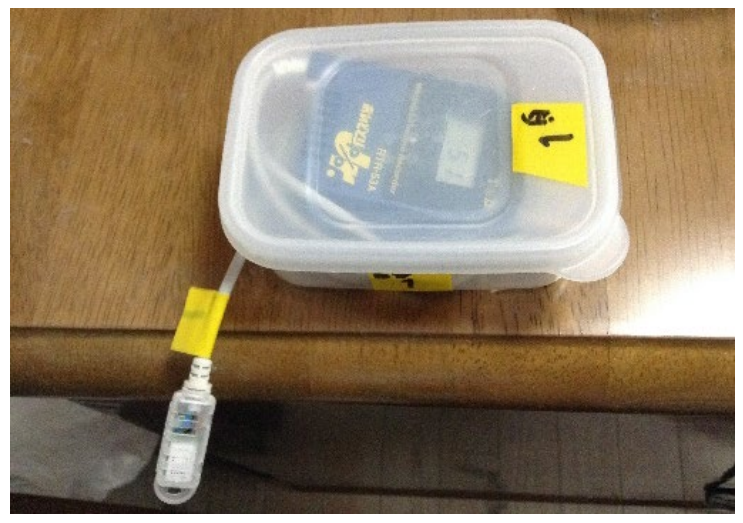

Figure 2: Measuring instrument in bedrooms [12]

Table 1: The detail of the instrument [9]

\begin{tabular}{ccc}
\hline Trade name & Range & Accuracy \\
\hline TR-74Ui & $0-55\left[{ }^{\circ} \mathrm{C}\right]$ & $\pm 0.5\left[{ }^{\circ} \mathrm{C}\right]$ \\
\hline
\end{tabular}

Table 2: Scales of thermal sensation and thermal preference

\begin{tabular}{cll}
\hline Scale & \multicolumn{1}{c}{ Thermal sensation } & Thermal preference \\
\hline 1 & Very cold & Much warmer \\
2 & Cold & A bit warmer \\
3 & Slightly cold & No change \\
4 & Neutral (neither cold nor hot) & A bit cooler \\
5 & Slightly hot & Much cooler \\
6 & Hot & \\
7 & Very hot & \\
\hline
\end{tabular}

\subsection{Analysis Method}

\subsubsection{Logistic regression}

The occupant behaviour stochastic model was calculated by logistic regression analysis. The function of logistic regression is:

$$
\operatorname{logit}(P)=a T_{o}+b
$$

The equation (1) is reformatted as

$$
P=\frac{e^{a T_{o}+b}}{1+e^{a T_{o}+b}}
$$

where $P$ is the proportion of air conditioning use and $T_{o}$ is outdoor air temperature $\left[{ }^{\circ} \mathrm{C}\right]$. This proportion " $P$ " means quantity rate of air conditioning opportunity. In this study, $P$ is replaced by $P_{C L}$ and $P_{H T}$ as the proportion of cooling use and heating use by air conditioner.

\subsubsection{Definition of excessive air conditioning use}


When the resident feel "cold" or "hot", we need to improve human health and save the energy. In this study, we defined the excessive air conditioning use by TSV or $\mathrm{TP}$. When the resident vote $\mathrm{TSV} \leq 3$ during the cooling use, we defined it as the excessive cooling use [7], and when the resident vote $5 \leq \mathrm{TSV}$ during the heating use, we defined it as the excessive heating use [8]. When the resident vote $\mathrm{TP} \leq 2$ during the cooling use, we defined it as the excessive cooling use, and when the resident voted $4 \leq \mathrm{TP}$ during the heating use, we defined it as the excessive heating use.

The models of excessive air conditioning use are calculated by the following relations:

$$
\begin{gathered}
P_{\text {exCL }}=P_{C L} \times P_{V c} \\
P_{\text {exHT }}=P_{H T} \times P_{V h}
\end{gathered}
$$

$P_{\text {exCL}}$ : proportion of excessive cooling use, $P_{C L}$ : proportion of cooling use, $P_{V c}$ : proportion of cold side (TSV $\leq 3$ ) during the cooling use, $P_{e^{*} H T}$ : proportion of excessive heating use, $P_{H T}$ : proportion of heating use, $P_{V h}$ : proportion of hot side $(5 \leq \mathrm{TSV})$ during the heating use.

In this study, we also defined the excessive air conditioning use for TP by the following equations:

$$
\begin{aligned}
& P_{\text {exCLtp }}=P_{C L} \times P_{V t p w} \\
& P_{\text {exHTtp }}=P_{H T} \times P_{V t p c}
\end{aligned}
$$

$P_{\text {exCLtp }}$ : proportion of excessive cooling use defined by TP, $P_{V t p w}$ : proportion of warmer side $(\mathrm{TP} \leq 2)$ during the cooling use, $P_{\text {exHTtp }}$ : proportion of excessive heating use defined by TP, $P_{V t p c}$ : proportion of cooler side $(4 \leq \mathrm{TP})$ during the heating use.

\section{Results and discussion}

In this study, the data were divided 3 modes: FR mode (free running - no cooling or heating being used), CL mode (cooling use) and HT mode (heating use).

\subsection{Outdoor and indoor air temperature}

In order to clarify the thermal environment in Japanese dwellings, Figure 3 shows the outdoor and indoor mean air temperature during the voting in each month. In each month, the mean indoor air temperatures are higher than outdoor. The range of outdoor air temperature was $23.2 \mathrm{~K}$ $\left(4.8^{\circ} \mathrm{C}\right.$ in January $-28.0^{\circ} \mathrm{C}$ in August). The range of indoor was $12.9 \mathrm{~K}\left(16.5^{\circ} \mathrm{C}\right.$ in February $-28.4^{\circ} \mathrm{C}$ in August). The range of outdoor is larger than indoor. It means that the climate of Japan has rich in four seasons with hot summer and cold winter. So, the residents need to select the suitable occupant behaviours in each season.

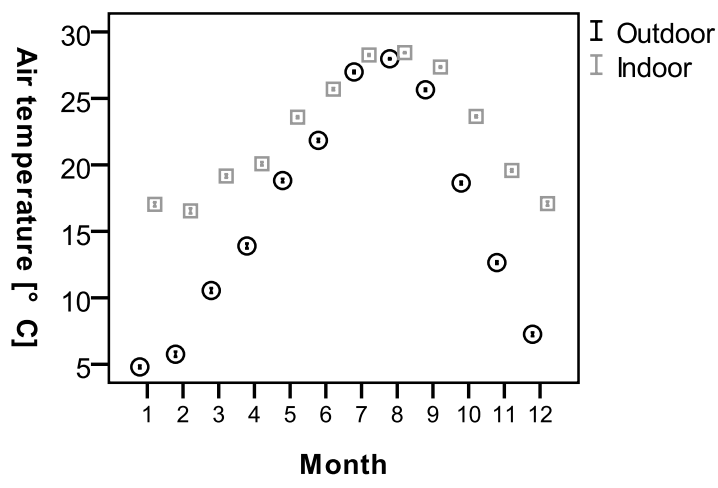

Figure 3: Mean outdoor and indoor air temperature in each month (at $95 \%$ confidence level: Mean \pm 2 S.E.).

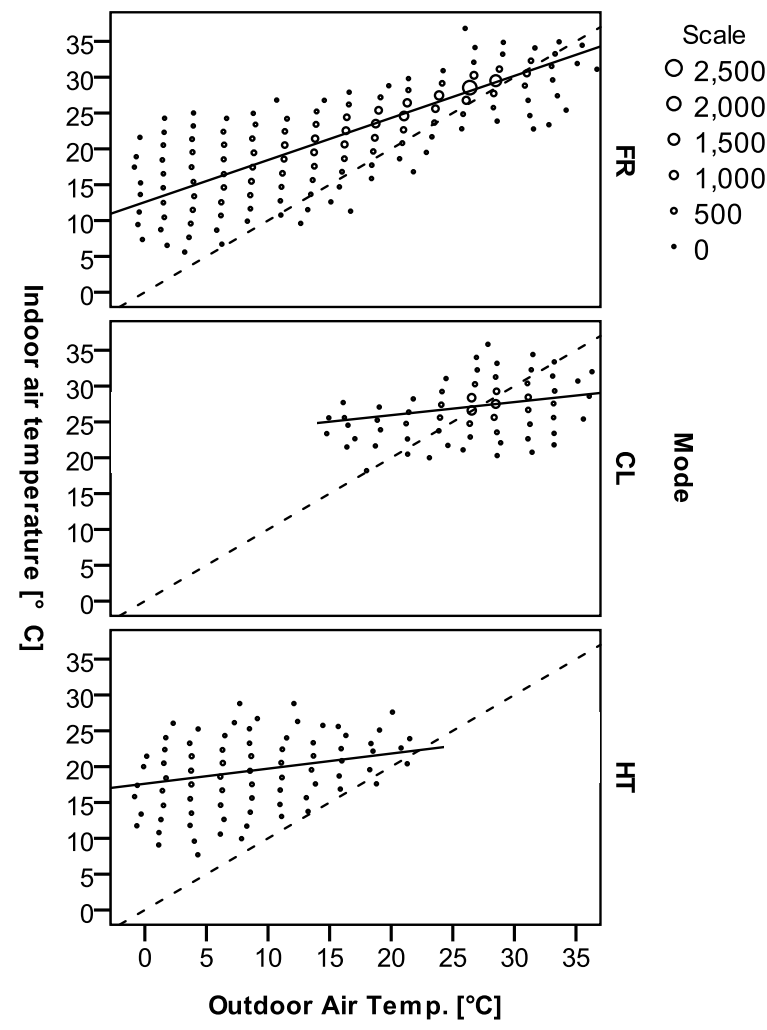

Figure 4: Relation between the indoor and outdoor air temperature in each mode

The Figure 4 shows the relations between indoor and outdoor air temperature during the voting in each mode. The solid lines show the regression line and the dot lines show "indoor air temperature $=$ outdoor air temperature". The spreads of scatters in FR mode show that the trend of indoor is higher the outdoor. The regression equations are shown below.

$$
\begin{gathered}
F R: T_{i}=0.587 T_{o}+12.6\left(\begin{array}{c}
n=25,180, R^{2}=0.785, \\
\text { S.E. }=0.002, p<0.001
\end{array}\right) \\
C L: T_{i}=0.183 T_{o}+22.3\left(\begin{array}{c}
n=6,405, R 2=0.068, \\
\text { S.E. }=0.008, p<0.001
\end{array}\right) \\
H T: T_{i}=0.211 T_{o}+17.6\left(\begin{array}{c}
n=3,065, R^{2}=0.082, \\
\text { S.E. }=0.013, p<0.001
\end{array}\right)
\end{gathered}
$$


Study on the Stochastic Model for Excessive Air Conditioning Use in Japanese Dwellings

$T_{i}$ : indoor air temperature $\left[{ }^{\circ} \mathrm{C}\right]$, $\mathrm{n}$ : number of samples, $\mathrm{R}^{2}$ : coefficient of determination, S.E.: standard error of the regression coefficient $\left[{ }^{\circ} \mathrm{C}\right], \mathrm{p}$ : significance level of the regression coefficient.

According to each regression lines, the difference between indoor and outdoor air temperature in CL and HT mode is larger than FR mode.

\subsection{The air conditioning use}

\subsubsection{Air conditioning use by month}

Figure 5 shows the proportions of cooling and heating use in each month. The residents often used the cooling in July - September, and heating in December - March. The maximum proportion of the cooling use is 0.47 in August, and the heating use is 0.45 in January. The residents used the air conditioning properly in each season.

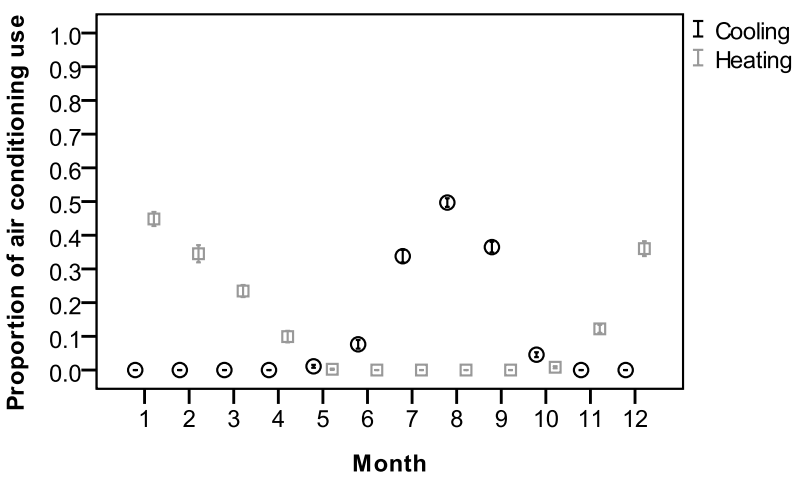

Figure 5: Proportion of air conditioning use in each month

\subsubsection{Relation between air conditioning use and outdoor air temperature}

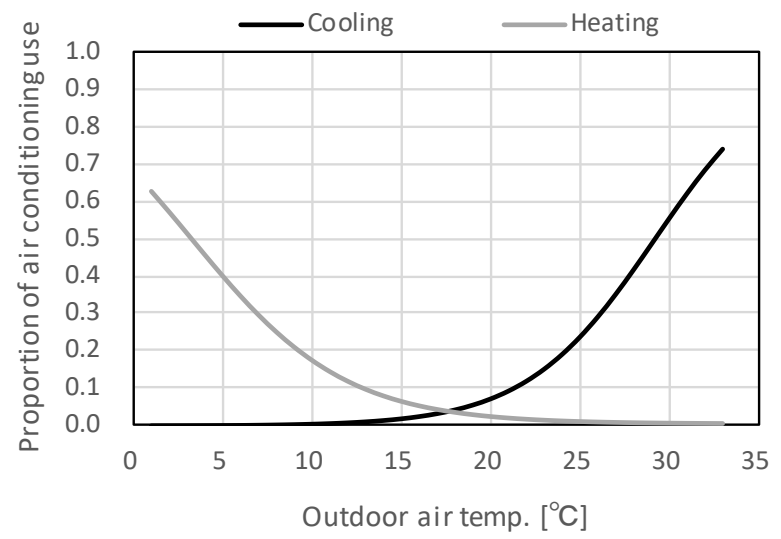

Figure 6: The stochastic model of cooling and heating use explained by outdoor air temperature

Figure 6 shows the proportion of heating or cooling use explained by outdoor air temperature. The regression equations are shown below.

$$
\begin{aligned}
& \operatorname{logit}\left(P_{C L}\right)=0.277 T_{o}-8.09\left(\begin{array}{c}
\mathrm{n}=34,681, \mathrm{R}^{2}=0.26, \\
\mathrm{~S} . \mathrm{E} .=0.004, \mathrm{p}<0.001
\end{array}\right) \\
& \operatorname{logit}\left(P_{H T}\right)=-0.233 T_{o}+0.755\left(\begin{array}{l}
n=30,568, R^{2}=0.199 \\
\text { S.E. }=0.004, p<0.001
\end{array}\right)
\end{aligned}
$$

The regression lines show that the cooling use was increased and heating use was decreased when outdoor air temperature was increased. When the outdoor air temperature was $17.3^{\circ} \mathrm{C}$, the proportion of cooling and heating use were 0.036 .

\subsection{Excessive air conditioning use}

\subsubsection{Proportion of excessive cooling or heating votes based on TSV}

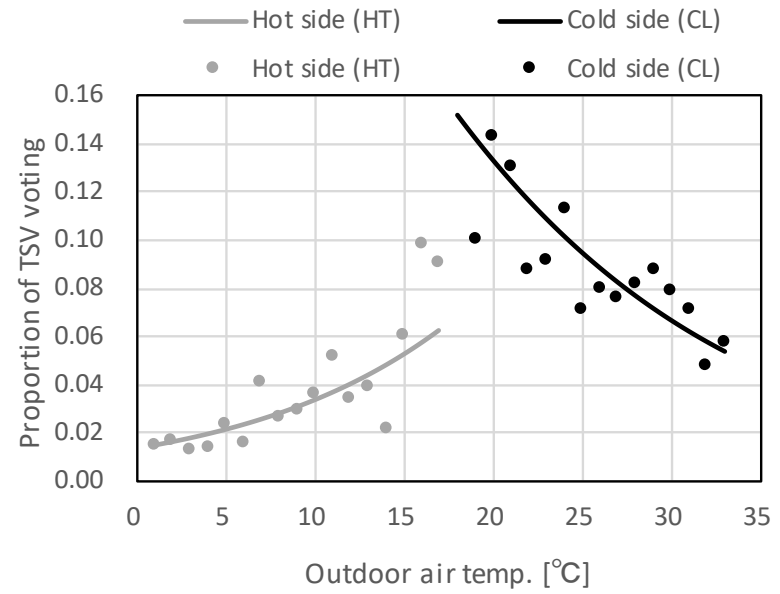

Figure 7: Proportion of excessive cooling or heating votes based on TSV explained by outdoor air temperature

Figure 7 shows the relation between the proportion of excessive cooling or heating votes based on TSV explained by outdoor air temperature $[7,8]$. The plots are the mean $P_{V c}$ and $P_{V h}$ for each $1 \mathrm{~K}$ of To. The regression analysis was conducted based on these scatter plots. The regression equations are shown below.

$$
\begin{gathered}
\operatorname{logit}\left(P_{V c}\right)=-0.077 T_{o}+0.333\left(\begin{array}{c}
\mathrm{n}=6,798, \mathrm{R}^{2}=0.003, \\
\text { S. E. }=0.016, \mathrm{p}<0.001
\end{array}\right) \\
\operatorname{logit}\left(P_{V h}\right)=0.093 T_{o}-4.285\left(\begin{array}{c}
n=3,187, R^{2}=0.004, \\
\text { S.E. }=0.024, p<0.001
\end{array}\right)
\end{gathered}
$$

The regression curves showed that $P_{V c}$ was increased and $P_{V h}$ were decreased when outdoor air temperature was increased. The overall trends showed that the $P_{V c}$ was larger than $P_{V h}$. From this, we can predict that the proportion of excessive cooling use is higher than excessive heating use. Thus, it can be said that the residents did not use cooling very well. 


\subsubsection{Proportion of excessive cooling or heating votes based on TSV explained by outdoor air temperature}

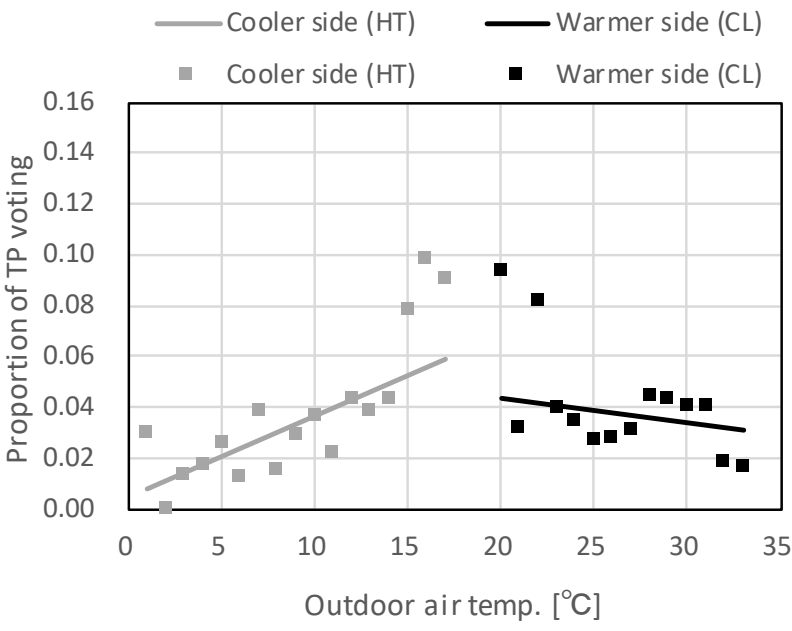

Figure 8: Proportion of excessive cooling or heating votes based on TP explained by outdoor air temperature

We try to clarify the difference of excessive air conditioning use between TSV and TP. Figure 8 shows the relation between the proportion of excessive cooling or heating votes based on TP explained by outdoor air temperature. The regression equations are shown below.

$$
\begin{aligned}
& \operatorname{logit}\left(P_{V t p w}\right)=-0.001 T_{o}+0.064\left(\begin{array}{l}
n=6,164, R^{2}=0.059 \\
S . E .<0.001, p<0.001
\end{array}\right) \\
& \operatorname{logit}\left(P_{V t p c}\right)=0.003 T_{o}+0.005\left(\begin{array}{l}
n=3,057, R^{2}=0.470 \\
\text { S.E. }<0.001, p<0.001
\end{array}\right)
\end{aligned}
$$

The trend of the regression lines of Figure 8 were similar to the Figure 7 in heating use. We can the understand that $P_{V t p c}$ was lower than $P_{V c}$. However, $P_{V t p w}$ was similar to $P_{V h}$.

\subsubsection{The model of excessive air conditioning use based on the TSV and TP}

Figure 9(a) shows the model of excessive cooling use classified by TSV or TP. In this figure, the solid lines are the regression line and the dot lines are the range of 2 standard error of regression coefficient. The regression line is not statistically significant at $95 \%$ confidence level. When the outdoor air temperature was increased, the proportion of excessive cooling use were increased in each TSV and TP. In addition, the excessive heating use was not statistically significant difference between TSV and TP.

Figure 9(b) shows the model of excessive heating use classified by TSV or TP. When the outdoor air temperature was increased, the proportion of excessive cooling use calculated by TSV was decreased, however the proportion of the excessive heating use calculated by TP was not only decreased but also increased in lower outdoor air temperature. In addition, the excessive heating use also was not statistically significant difference between TSV and TP.
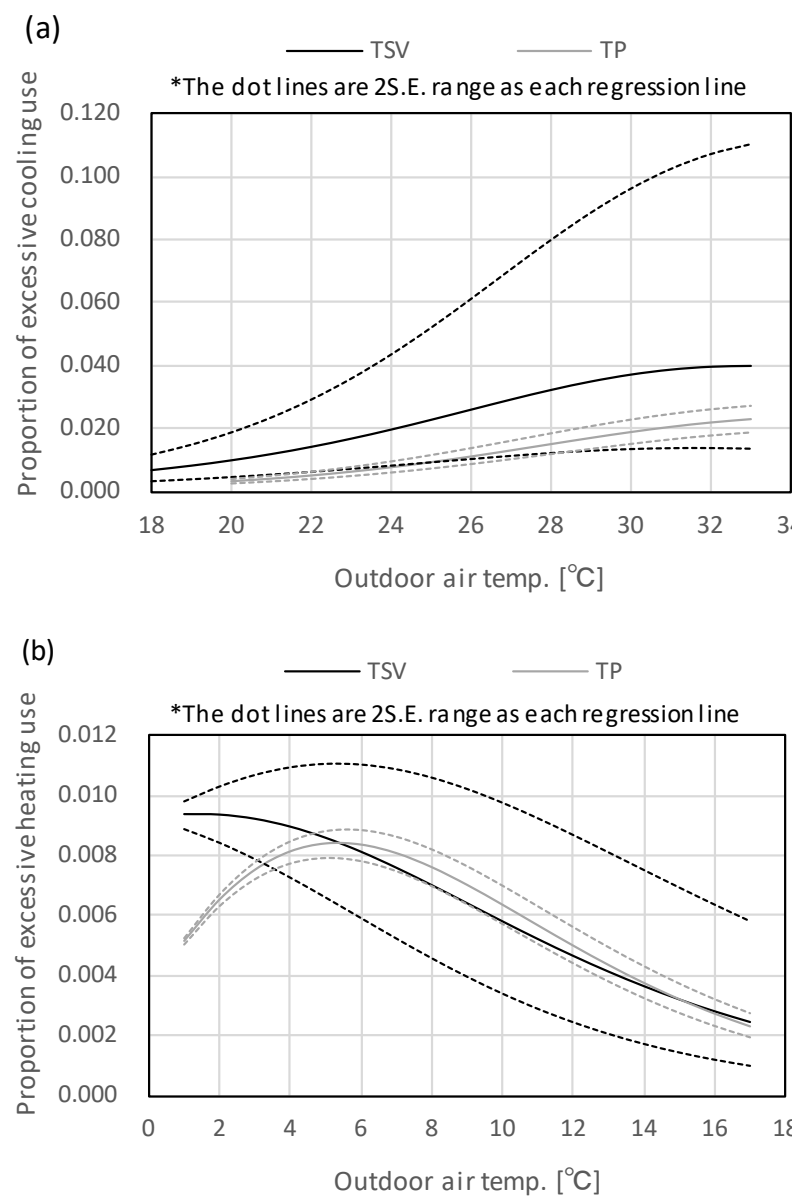

Figure 9: The model of excessive air conditioning use explained by outdoor air temperature

In this section, the proportion of excessive cooling and heating use were changed by outdoor air temperature, and there was no significant difference between the TSV and TP for calculating.

\section{Conclusions}

In order to clarify the excessive air conditioning use in Japanese dwellings, we have conducted thermal measurement, thermal comfort survey and occupant behaviour survey in 120 Japanese dwellings during 4 years periods. We have found the following results.

- The range of outdoor and indoor air temperature were wide. It means that the climatic condition of Japan has rich with hot summer and cold winter. So, the residents need to select the suitable occupant behaviours in each season. 
- The residents often used the cooling in July September, and heating in December - March. The residents used the air conditioning properly in each season.

- The proportion of cooling use was increased and heating use was decreased when the outdoor air temperature was increased.

- The proportion of excessive cooling votes were decreased and excessive heating votes were increased when outdoor air temperature was increased.

- The stochastic model of the excessive air conditioning use was calculated. There in not statistically difference of excessive air conditioning use between thermal sensation scale (TSV) and thermal preference (TP).

The reason might be that the residents can select suitable occupant behaviour in the dwellings. If we investigate in the public space such as office, classroom, station and restaurant etc., there would be some difference between thermal sensation and thermal preference. Because we cannot select the suitable thermal adjustment easily in public space.

In the future, when we will conduct survey in public space, we would like to analyse the model of excessive air conditioning use.

\section{Acknowledgments}

The authors are thankful to occupants who participated in the survey and all the lab members for data entry. This research was supported by the Japan Society for the Promotion of Science, Grant-in-Aid for Scientific Research (c) 17K06681.

\section{References}

[1] Sawachi T, Matsuo Y, Hatano K and Fukushima H (1987), Determinants of heating and air conditioning behavior, and acceptable ranges of temperature based on behavior-study on residents' behavior contributing to formation of indoor climate, part 1-, Journal of Architecture, Planning and Environmental Engineering, 382: 48-59.

[2] Habara H, Narumi D, Shimoda Y and Mizuno M (2005), A study on determinants of air conditioning on/off control in dwellings based on survey, Journal of environmental engineering, 40 (589): 83-90.

[3] Schweiker M and Shukuya M (2008), Investigation on the relationship between occupants' individual difference and air-conditioning usage during nighttime in summer, Journal of Environmental Engineering (transactions of AIJ), 73(625): 1275-1282

[4] Habara H (2015), Logistic regression analysis of factors affecting occupants' air conditioner/window operating behavior in living rooms -field survey on occupants' window opening /air conditioner using behavior in dwellings-, Journal of environmental engineering, 80 (715): 827-837.

[5] Takasu M, Ooka R, Rijal HB, Indraganti M, Singh MK (2017), Study on adaptive thermal comfort in Japanese offices under various operation modes, Building and Environment, 118: 273-288.

[6] Kim J, de Dear R, Parkinson T and Candido C (2017) Understanding patterns of adaptive comfort behaviour in the Sydney mixed-mode residential context, Energy and Buildings, 141: 274-283.

[7] Imagawa H and Rijal HB (2017), Study on cooling use and coldness in dwellings, Technical papers of annual meeting, the Society of Heating, Air-Conditionings and Sanitary Engineers of Japan, 8: 313-316

[8] Imagawa H, Rijal HB and Shukuya M (2018), A study on the heating use and hotness in dwellings, Technical papers of annual meeting, the Society of Heating, AirConditionings and Sanitary Engineers of Japan, 8: 249252

[9] Rijal HB, Humphreys MA and Nicol JF (2018), Development of a window opening algorithm based on adaptive thermal comfort to predict occupant behavior in Japanese dwellings, Japan Architectural Review, 1(3): 310-321

[10] Jukankyo Research Institute Inc. (2013), The handbook of energy for family, The energy conservation center, Japan

[11] Ministry of land, infrastructure, transport and tourism, Searching the past data of climate, accessed online at http://www.data.jma.go.jp/obd/stats/etrn/index.php

[12] Imagawa H and Rijal HB (2015), Field survey of the thermal comfort, quality of sleep and typical occupant behaviour in the bedrooms of Japanese houses during the hot and humid season, Architectural Science Review, 58(1): $11-23$ 